\title{
3D Numerical Simulation of Heat Transfer of a Heated Plate under the Electric Field Generated by a Needle Electrode
}

\author{
Jianfei Zhang, Chu Zhao, Hongyan Li, and Wenquan Tao \\ Key Laboratory of Thermo-Fluid Science and Engineering, Ministry of Education, School of Power and Energy Engineering, \\ Xian Jiaotong University, Xian 710049, China
}

Correspondence should be addressed to Jianfei Zhang; zhangjf@mail.xjtu.edu.cn

Received 1 July 2014; Accepted 2 September 2014; Published 25 September 2014

Academic Editor: Gongnan Xie

Copyright (C) 2014 Jianfei Zhang et al. This is an open access article distributed under the Creative Commons Attribution License, which permits unrestricted use, distribution, and reproduction in any medium, provided the original work is properly cited.

A three-dimensional numerical model that couples the electric field, velocity field, and temperature field is developed based on the commercial code COMSOL Multiphysics. The influences of several factors on convective heat transfer on a heated plate in the electric field generated by a needle electrode are observed. The factors are the applied voltage, the distance between the two electrodes, and the size of the ground plate. The results show that applied voltage is one of the most important factors for the convection heat transfer. The convection heat transfer efficiency significantly increases with the improvement of the applied voltage. From the perspective of the model size, the decrease of the distance between two electrodes and the size of the plate could improve the average convection heat transfer coefficient. Smaller ionic wind device needs lower applied voltage and less electric energy to obtain the same average convection heat transfer coefficient as the bigger one, which provides the theoretical basis for the potential of miniaturizing the ionic wind cooling device.

\section{Introduction}

Air is widely applied as heat transfer medium due to its abundant amount and safety, but at the same time it is also a medium with poor heat transfer performance. Great efforts have been made for the enhancement of heat transfer for air. A method called ionic wind cooling which introduces the electric field to the enhancement of air convection heat transfer attracts many researchers' interests recently. Ionic wind cooling is a technology based on the electrohydrodynamics (EHD) theory. By applying high-voltage electric field between a sharp electrode and a grounded surface in the air, molecules in the air are ionized and the positive ionized air molecules are accelerated by the electrostatic force. Then they transfer their kinetic energy to the neutral air molecules by collisions, thus leading to a movement of airflow. The advantages of ionic wind cooling include convenient control, low energy consumption, no moving parts, long lifespan, high potential of integration, and miniaturization.

In the past few years there have been many studies related to the flow and heat transfer characteristics of ionic wind and the development of ionic wind or EHD pumps. Moreau and Touchard [1] experimentally investigated the influence of different parameters, including the polarity, the electrode geometry, the distance between electrodes, and the diameter of the tube, on the characteristics of ionic wind, and they found that the air speed generated from positive corona discharge is higher than negative one. Kasayapanand [2-5] conducted a series of numerical simulations of electric field effect on natural convection of air, and the results showed that the natural convection heat transfer of air could be greatly enhanced. Mahmoudi et al. [6] experimentally and numerically investigated the natural convection heat transfer of an isothermal horizontal cylinder under the electrical field, and a blade edge emitter electrode was used. It was found that the enhancement of heat transfer through the corona discharge is stronger for lower $R a$ numbers. Go et al. [7] discussed the local heat transfer enhancement by inducing ionic wind in the existing bulk flows. The experiment data and multiphysics simulation results showed that the ionic wind could distort the bulk flow boundary layer and more than twofold enhancement of local heat transfer coefficient was achieved. Go et al. [8] also performed an experimental measurement of heat transfer enhancement of a flat plate 
by ionic wind. The infrared images showed that the local heat transfer coefficient is increased by more than two times compared with those obtained from bulk flow only. And they also presented analytical derivation and experimental results to prove that the heat transfer coefficient should be related to the fourth root of the corona current. Ahmedou and Havet [9] studied the heat transfer process under high voltage in the channel by means of numerical simulation. The results showed that different combinations of electrodes and applied voltages can generate similar flow, and a reasonable arrangement can enhance the heat transfer up to 10 times. Pour and Esmaeilzadeh [10] experimentally investigated the convective heat transfer enhancement of a cylindrical heat source by using EHD actuator in a duct. They found that the electric field is more effective for the heat transfer enhancement at low Reynolds number. Alamgholilou and Esmaeilzadeh [11] performed an experimental study on the heat transfer enhancement on ribs in a rectangular duct by using passive, active, and compound methods with application of corona wind. The results indicated that the compound method for lower Reynolds number has higher efficiency of enhancement. A kind of EHD miniature solid-state fan was presented by Schlitz and Singhal [12]. The fan has thickness of $1 \mathrm{~mm}$ and no moving parts, but the wind velocity could reach up to $1.6 \mathrm{~m} / \mathrm{s}$. The authors intended to integrate the fan into an integrated, chip-scale cooling system or to replace the blower in a laptop cooling system. Jewell-Larsen et al. [13] successfully integrated the EHD cooling system into a laptop computer and compared the EHD cooling system with the traditional fan cooling system. They found that the EHD cooling system possesses higher heat transfer performance, lower energy consumption, and less noise. Jewell-Larsen et al. [14] also discussed the effects of dust accumulation in the EHD cooling system and presented a numerical model of the dust deposition.

To further strengthen the ionic wind, some researchers focus on the utilization of multielectrodes or multistage discharge structures. Huang et al. [15] presented an experimental study on four kinds of needle-arrayed electrodes combined with a plate fin heat sink, and the results showed that the negative corona has a lower threshold voltage and a better performance compared with the positive one. The enhancement ratio was around 3 to 5 for moderate test condition. Tirumala and Go $[16,17]$ proposed a multicollecting electrodes method to establish the miniaturized EHD cooling system, which could greatly improve the effectiveness of heat transfer due to the increasing of the current. Zhang and Lai [18] investigated the relation between the electrode number and EHD gas pump performance using experimental measurements and numerical simulations. They concluded that when applied voltage is lower than $24 \mathrm{kV}$, the negative corona can produce velocity and volume flow rate higher than positive corona, and this trend will be reversed at a higher applied voltage. The proposed EHD gas pump with 4 emitting electrodes can induce more flows than others at low voltages and it is more effective than most conventional fans. Mazumder and Lai [19] also proposed an EHD pump with two-stage, and the maximum performance of $34 \mathrm{~L} / \mathrm{s}$ can be achieved by using totally 56 electrodes with 0.5 inch wide grounded plate in each stage. However, in this study only positive corona discharge was considered. In [20] Wang et al. described the breakthrough in the development of electrostatic fluid accelerators (EFA) and its applications in the microelectronics cooling. Comparisons between EFAs' performance and those of other airside cooling technologies were also presented. It was concluded that EFAs have great potential becoming a novel and performance-improved airside thermal management solution for advanced microelectronics.

Given the above, it can be seen that a major part of studies is based on experiment tests, which can provide reliable test data, but is costly and time consuming. With the development of computer technologies and multiphysics simulation methods, numerical simulation begins to play a more important role. Compared to experiment, numerical simulations can provide more detailed information at much lower cost. The numerical simulation methods for the flow and heat transfer characteristics of ionic wind are still in progress. Most of the numerical studies mentioned in the literature above adopt two dimensional models, which are far away from the practical situation. The numerical methods of some researches are not clearly illustrated, especially for the determination of the space charge. Moreover, some simulation results even lack validation with experimental data. All of these motivate the present studies.

In this paper, a 3-dimensional needle-plate model will be established by using commercial code COMSOL Multiphysics. The establishment of the numerical model and the numerical method will be given in details. To verify the reliability of the numerical method, the numerical results will be compared with the experimental results from open literatures. The influence of different factors, including the voltage, the distance between the two electrodes, and the size of the ground plate on the heat transfer, will be discussed.

\section{Theoretical Analysis and Equations}

Governing equation for electric field is as follows:

$$
\nabla^{2} V=-\frac{q}{\varepsilon_{0}},
$$

where $q$ is charge density, $\varepsilon_{0}$ is dielectric permittivity, and the relation between voltage $V$ and electric field intensity $\vec{E}$ is

$$
\vec{E}=-\nabla V
$$

The current continuity equation is

$$
\Delta \vec{J}=0,
$$

where electric current density $\vec{J}$ is described as

$$
\vec{J}=\mu_{E} \vec{E} q+\vec{U} q-D \nabla q .
$$

The three terms on the right side of the equation are expressed as charge conduction (the ion movement relative to the overall flow under the electric field), charge convection (charge movement generated by the air flow), and charge 
diffusion (thermal motion of charge), respectively. The ionic mobility $\mu_{E}$ is $2 \times 10^{-4}$ for positive voltage and $2.7 \times 10^{-4}$ for negative voltage. And the first term on the right side contributes the most in the equation.

As the speed of ions is considerably higher than the speed of air flow, the influence of air flow on ionic movement could be ignored; that is, the influence of air velocity on current density could be ignored. Furthermore, the diffusion coefficient of ionic is so small that it can be also ignored. Thus, the electric current density in present study can be simplified as

$$
\vec{J}=\mu_{E} \vec{E} q
$$

The mass conservation equation is

$$
\nabla \cdot \vec{U}=0
$$

where $\vec{U}$ is velocity.

The momentum equation is

$$
\vec{U} \cdot \nabla(\vec{U})=-\frac{1}{\rho} \nabla p+\nu \nabla^{2} \vec{U}+\frac{\overrightarrow{F_{E}}}{\rho},
$$

where $\rho$ is the density of the air, $p$ is pressure, and $\overrightarrow{F_{E}}$ is the electric field force given by

$$
\overrightarrow{F_{E}}=q \vec{E}-\frac{1}{2} \vec{E}^{2} \nabla \varepsilon+\frac{1}{2} \nabla\left[\vec{E}^{2}\left(\frac{\partial \varepsilon}{\partial \rho}\right) \rho\right] .
$$

The first term on the right side of the equation is Coulomb force. The second term is called dielectrophoretic force generated by the change of dielectric constant space. The third term is electrostrictive force, which is the gradient force due to the change of the dielectric constant and is caused by the different density. In this paper the working fluid is air, and among all the forces the Coulomb force is the majority. The electric field force can be simplified as

$$
\overrightarrow{F_{E}}=q \vec{E}
$$

The energy equation is

$$
\nabla \cdot(\vec{U} T)=\nabla \cdot\left(\frac{\lambda}{\rho c_{p}} \nabla T\right)+\frac{Q_{E}}{\rho c_{p}},
$$

where $T$ is temperature, $c_{p}$ is the specific heat, and $Q_{E}$ is the joule heat generated by the movement of the ionic:

$$
Q_{E}=\vec{J} \cdot \vec{E}=\mu_{E} q \vec{E}^{2} .
$$

\section{Methodology}

3.1. Determination of Space Charge. Generally, there are two ways to determine the distribution of space charge in the simulation of ionic wind. The first one is to calculate the ionization zone (close to the corona electrode and in which air ionization occurs) and drift zone (located between the ionization zone and the ground electrode) at the same time and then analyze the motion of microscopic particle to calculate the detailed distribution of space charge. The second one is to calculate the drift region only by assuming a charge density value at the interface crossing the ionization zone and the drift area. The latter method is mostly adopted in numerical studies of ionic wind for the reason that, in the area of convection heat transfer, the major task is to investigate the macroscopic heat transfer phenomena in the drift region. Moreover, this kind of method can also avoid the difficulties in the simulation of ionization zone.

Careful attention needs to be paid on how to determine the charge density at the interface crossing the ionization zone and the drift area. In this paper, a method of try and error iteration is used. Firstly, a guessed charge density at the external surface of ionic zone is given to calculate the current, and the calculated intensity of electric current should be around the level of $\mu \mathrm{A}$ to $\mathrm{mA}$. Then the current value will be compared with the experimental data. If the error is reasonable the assumption of charge density will be proved to be rational; if not, then repeat the prediction and validation process. The error in present study is controlled by

$$
\left|\frac{I_{\text {num }}-I_{\text {exp }}}{I_{\exp }}\right| \leq 5 \% \text {. }
$$

In many cases, the experiment data is not available in advance and it is costly and time-consuming to obtain experimental data for the validation of every simulation case. Therefore, an empirical formula is adopted to calculate the current for needle-plate discharge structure when the experimental data are not available. The empirical formula is as follows [21]:

$$
I_{\mathrm{cal}}=\frac{1.58 \mu_{E} \varepsilon_{0} V\left(V-V_{E}\right)}{d},
$$

where $V_{E}$ is inception voltage.

According to Peek's semiempirical formula [22],

$$
V_{E}=\frac{1}{2} E_{b} R_{n}\left(1+\frac{0.03}{\sqrt{R_{n}}}\right) \ln \left[\left(\frac{2 d}{R_{n}}\right)+1\right],
$$

where $E_{0}$ is breakdown electric field intensity, $d$ is distance between two electrodes, and $R_{n}$ is radius of the needle electrodes.

3.2. Solution Procedure. The solution procedure of this paper is shown in Figure 1. First of all, the Poisson equation and the current continuity equation are solved with the assumption of the boundary condition of the space charge. When the calculated current is proved to be reasonable, put the electric force into the momentum equation to obtain the flow field distribution. Finally, solve the energy equation and obtain the heat transfer results.

\section{Validation the Simulation Method}

4.1. The Simulation Model. The experimental model (Design A) in [23] is used to validate the rationality of the simulation 


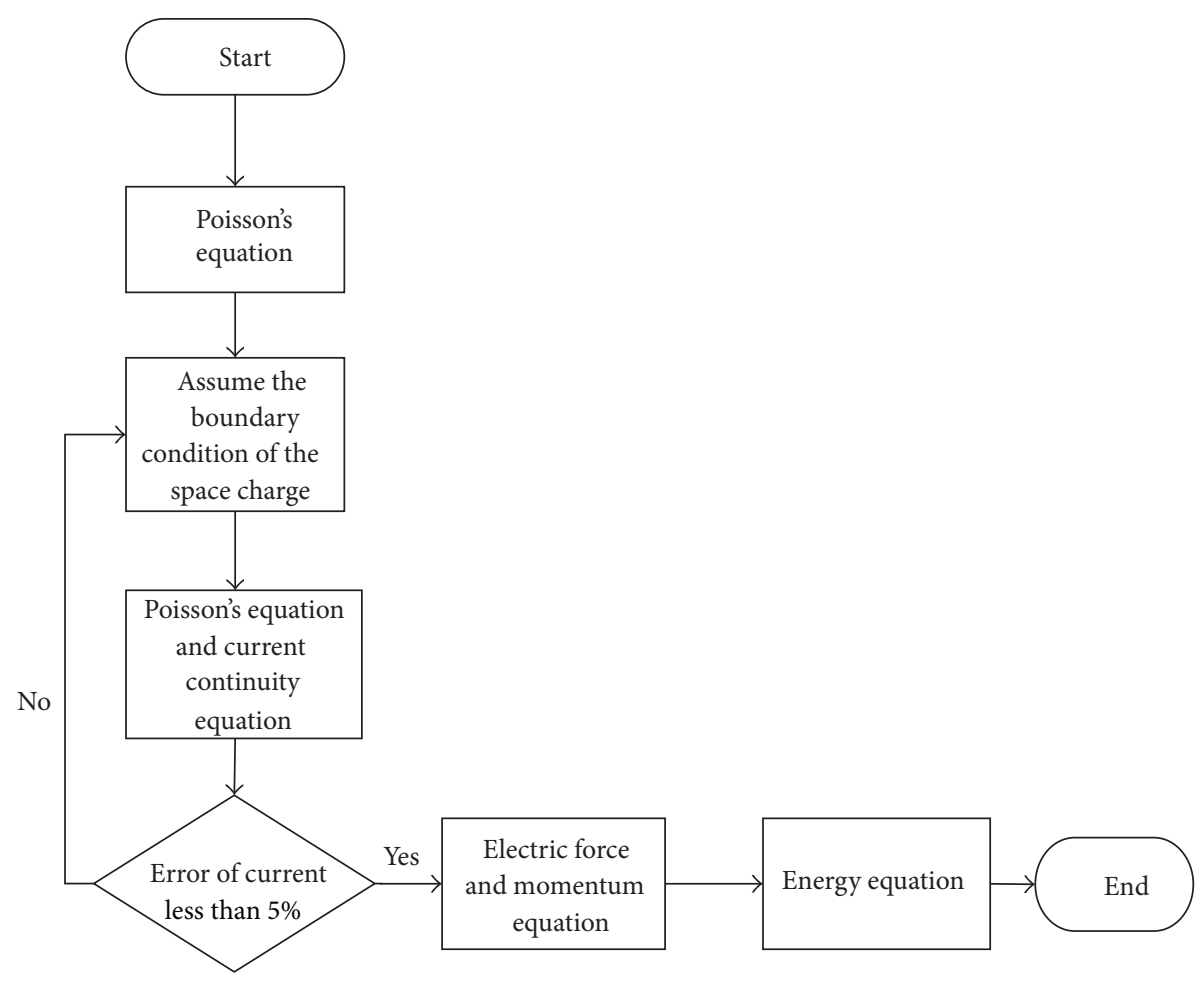

FIGURE 1: Solution procedure.

method. The calculation model is shown in Figure 2. For the simplification of the simulation, heat conduction of the ground electrode is not considered, and the thickness of the ground electrode is ignored.

The boundary conditions are shown in Figure 3 and Table 1, where A indicates the needle electrode, $\mathrm{B}$ indicates the ground electrode, $\mathrm{C}$ is the surface where the needle electrode located, and D represents the sides of the model.

Assumptions are made in this paper as follows according to the numerical studies done by other authors in the past [2$5,20,21,24]$ : the high voltage is stable and positive, the ionic mobility is constant, the influence of ion diffusion and the influence of the magnetic field are ignored, the influence of humidity of air is ignored, and the density of the space charge is zero at the inlet and outlet of model to ensure a well-posed problem.

The physical parameters used in the simulation are shown in Table 2.

\subsection{Validation of Numerical Model}

4.2.1. Grid Independent Test. By adjusting the density of grids in COMSOL Multiphysics, five grid systems with $36446,71682,133341,336238$, and 823603 cells are adopted for calculation. The difference in the average heat transfer coefficient between last two grid systems is around $1 \%$, as shown in Figure 4. So the fourth grid system is taken for the computation (see Figure 5).

The electrostatic field distribution, space charge distribution, velocity field distribution, and temperature field

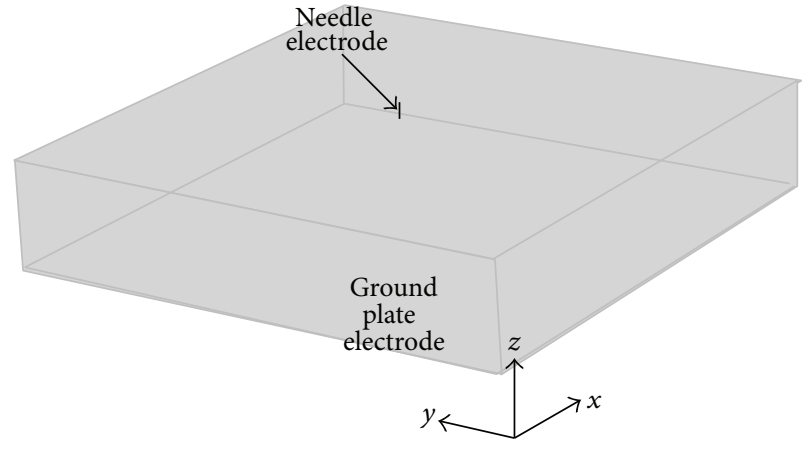

FIGURE 2: Calculation model.

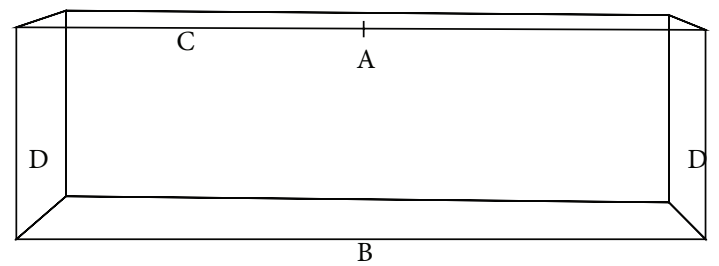

FIgURE 3: Positions of boundaries.

distribution can be found in Figure 6. The larger velocities toward the ground plate (see Figure 6(c)) around the needle electrodes can be observed due to the high density of electric field in this region (see Figures 6(a) and 6(b)). Therefore, the higher temperature gradient at the central area of the ground 
TABLE 1: Boundary conditions of validation model.

\begin{tabular}{lcccc}
\hline & Electrostatics & Charge transport & Fluid dynamics & Heat transfer \\
\hline A & Voltage applied & Surface charge density & No slip & Thermal insulation \\
B & Grounded & Zero diffusive flux & No slip & Constant temperature \\
C & Zero charge & Zero diffusive flux & Neutral pressure & Thermal insulation \\
D & Zero charge & Zero diffusive flux & Neutral pressure & Thermal insulation \\
\hline
\end{tabular}

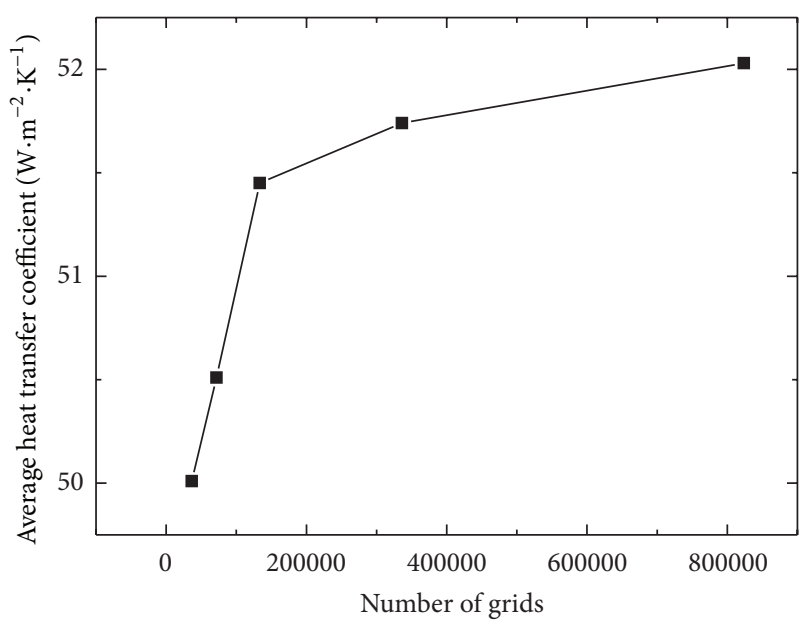

Figure 4: Grid independence test.

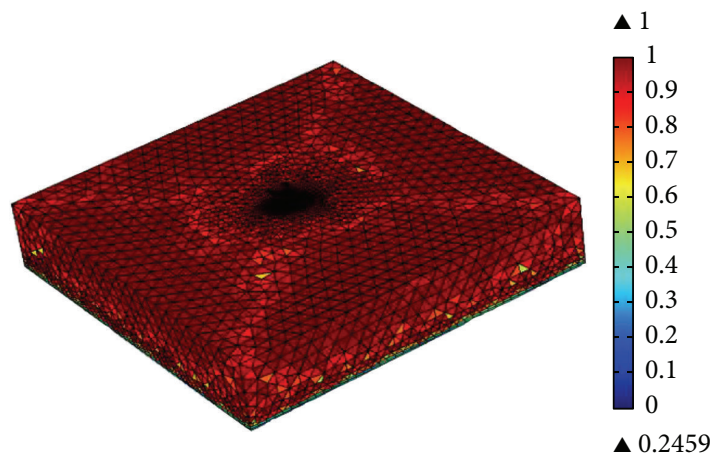

FIGURE 5: Grid system and gird quality check.

plate can be found in Figure 6(d), which means that the ionic wind is more efficient for the requirements of local cooling.

4.2.2. Validation of Current. The current value based on the simulation results can be derived by

$$
I_{\text {num }}=2 \pi \mu_{E} \varepsilon_{0} E_{g}^{2},
$$

where $E_{g}$ is electric field intensity on the ground electrode.

Figure 7 presents the simulation current values of this paper and the experimental data from literature [23] for the voltage of $4.5 \mathrm{kV}, 5 \mathrm{kV}, 6 \mathrm{kV}$, and $7 \mathrm{kV}$, respectively. The maximum deviation between the simulation results and the experiment results is around $-3.3 \%$. Thus, the numerical method for the electric field calculation is proved to be reliable.
TABLE 2: Physical parameters.

\begin{tabular}{lc}
\hline Parameters & Value \\
\hline$\mu_{E}$ & $2.0 \times 10^{-4} \mathrm{~m}^{2} /(\mathrm{v} \cdot \mathrm{s})$ \\
$\varepsilon_{0}$ & $8.85 \times 10^{-12} \mathrm{~F} / \mathrm{m}$ \\
$\rho_{\text {air }}$ & $1.23 \mathrm{~kg} / \mathrm{m}^{3}$ \\
$\nu_{\text {air }}$ & $14.8 \times 10^{-6} \mathrm{~m}^{2} / \mathrm{s}$ \\
$c_{p}$ & $1.007 \mathrm{~kJ} /(\mathrm{kg} \cdot \mathrm{K})$ \\
$\lambda_{\text {air }}$ & $0.027 \mathrm{~W} /(\mathrm{m} \cdot \mathrm{K})$ \\
\hline
\end{tabular}

4.2.3. Validation of Heat Transfer. The local convection heat transfer coefficient is defined by

$$
h_{x}=\frac{q_{t}}{\Delta T_{x}} .
$$

The average convection heat transfer coefficient is expressed as

$$
h_{\mathrm{avg}}=\frac{1}{A} \int h_{x} \mathrm{~d} A \text {. }
$$

As shown in Figure 8, the results of the average heat transfer coefficient which were obtained from the simulation agree well with the experimental data from [23]. And the maximum deviation is around $-3.5 \%$. This verifies the accuracy of the present numerical method.

\section{Results and Discussion}

5.1. Numerical Model. The physical models discussed in following parts are similar to the validation model. Based on the consideration of ongoing trends of microminiaturization of the ionic wind devices, smaller plate is employed in the simulation. Besides, considering the convenience of manufacture, the radius of the needle electrode is at the level of micrometer scale. Most of the boundary conditions of the models are the same as the validation model. The only difference is that the constant temperature condition is changed to constant heat flux condition for the plate, and the heat flux is $10^{4} \mathrm{~W} / \mathrm{m}^{2}$. Heat transfer enhancement ratio $\Gamma$ is induced to illustrate the effectiveness of the heat transfer, which is defined as

$$
\Gamma=\frac{h_{\mathrm{EHD}}}{h_{\text {free }}},
$$

where $h_{\mathrm{EHD}}$ is the average convection heat transfer coefficient under electric field, $h_{\text {free }}$ is the average convection heat transfer coefficient under natural convection, and the value of $h_{\text {free }}$ is taken as $10 \mathrm{~W} / \mathrm{m}^{2} \cdot \mathrm{K}$. 


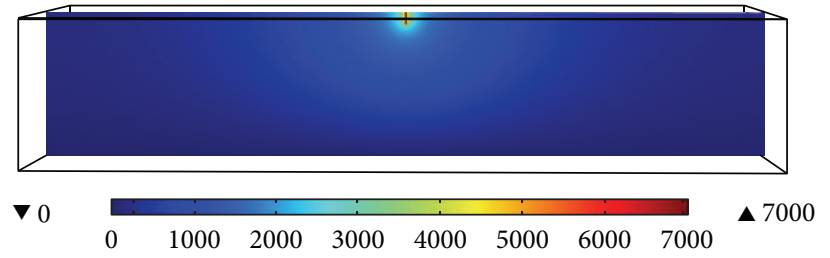

(a) Distribution of voltage

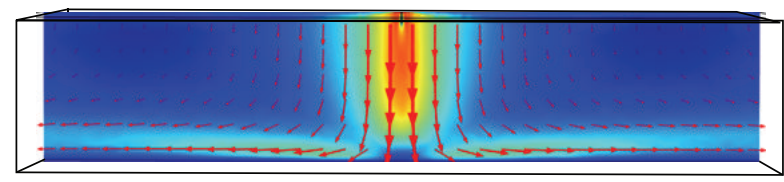

$\nabla 0$
0

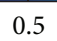

(c) Distribution of velocity

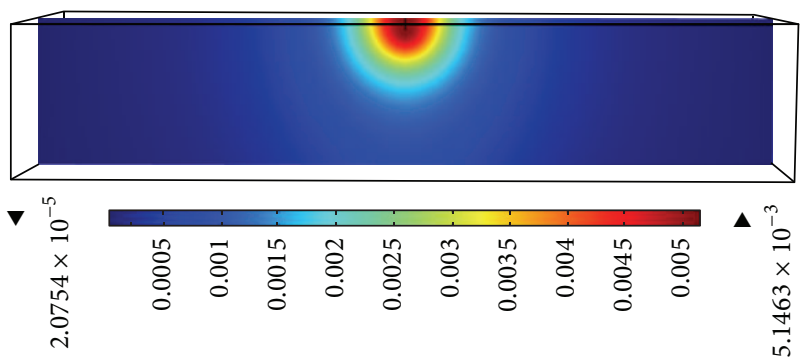

(b) Distribution of space charge

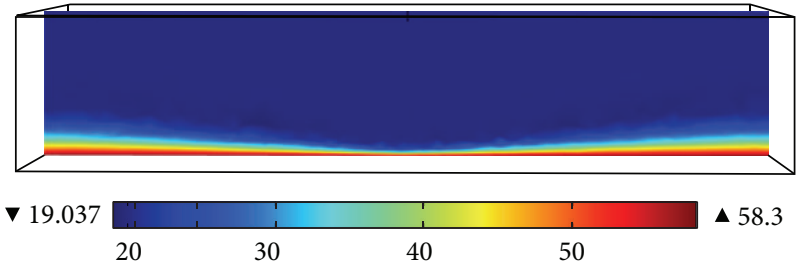

(d) Distribution of temperature

FIGURE 6: Results of the simulation ( $V=7 \mathrm{kV}, x-z$ plane through the needle electrode).

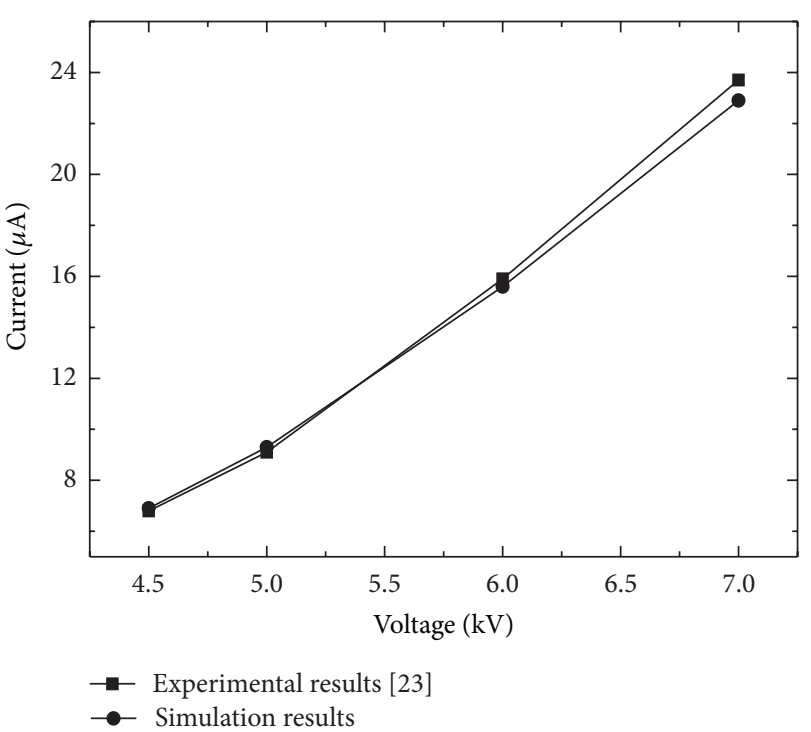

FIGURE 7: Comparison of current.

5.2. Effect of Voltage on Heat Transfer. In this section six different voltages are investigated, including $4 \mathrm{kV}, 4.5 \mathrm{kV}$, $5 \mathrm{kV}, 6 \mathrm{kV}, 7 \mathrm{kV}$, and $8 \mathrm{kV}$. The geometric dimension of the plate is $5 \mathrm{~mm} \times 5 \mathrm{~mm}$. The distance between two electrodes is $5 \mathrm{~mm}$. And the radius of the needle electrode is $8 \times 10^{-3} \mathrm{~mm}$.

As shown in Figure 9, the average heat transfer coefficient and the maximum velocity increase significantly with the improvement of the voltage; for example, the average heat transfer coefficient increases from $86.05 \mathrm{~W} / \mathrm{m}^{2} \cdot \mathrm{K}$ at the voltage of $4 \mathrm{kV}$ to $133.74 \mathrm{~W} / \mathrm{m}^{2} \cdot \mathrm{K}$ at the voltage of $8 \mathrm{kV}$. Higher applied voltage generates higher density of electric field and higher ionic wind velocity and then results in higher convection heat transfer coefficient. However, the

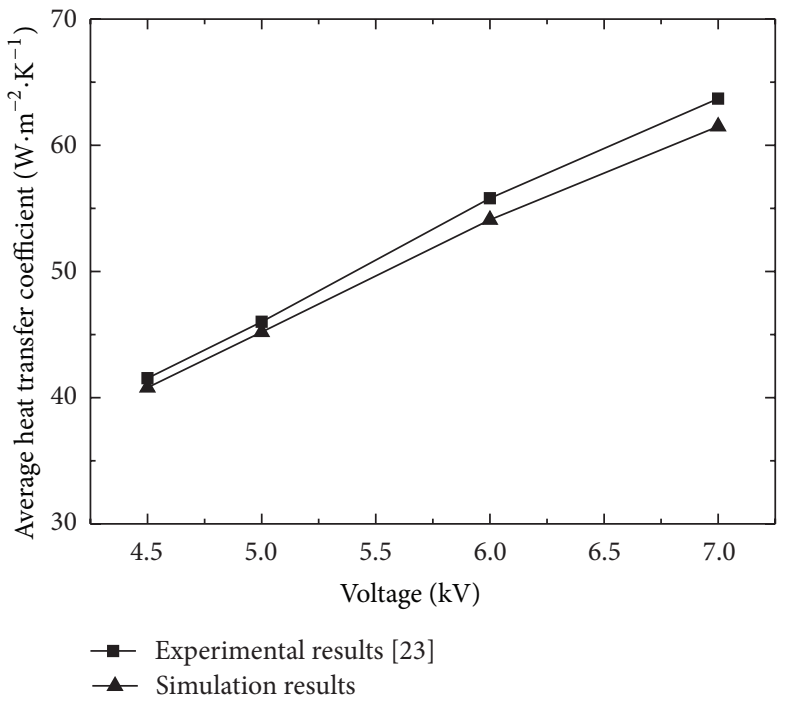

FIgURE 8: Comparison of heat transfer.

improvement of applied voltage is limited by the air gap breakdown voltage.

5.3. Effect of Distance between Two Electrodes on Heat Transfer. In this section the effect of the distance between the needle electrode and the ground electrode on heat transfer will be discussed. Five different distances including $3 \mathrm{~mm}, 4 \mathrm{~mm}$, $5 \mathrm{~mm}, 6 \mathrm{~mm}$, and $7 \mathrm{~mm}$ are considered. The geometric dimension of the plate is $5 \mathrm{~mm} \times 5 \mathrm{~mm}$. The applied voltages are $6 \mathrm{kV}, 7 \mathrm{kV}$, and $8 \mathrm{kV}$. The radius of the needle electrode is $8 \times 10^{-3} \mathrm{~mm}$.

The change of the average convection heat transfer coefficients with the variation of the distance between two electrodes is shown in Figure 10. It can be observed that the 


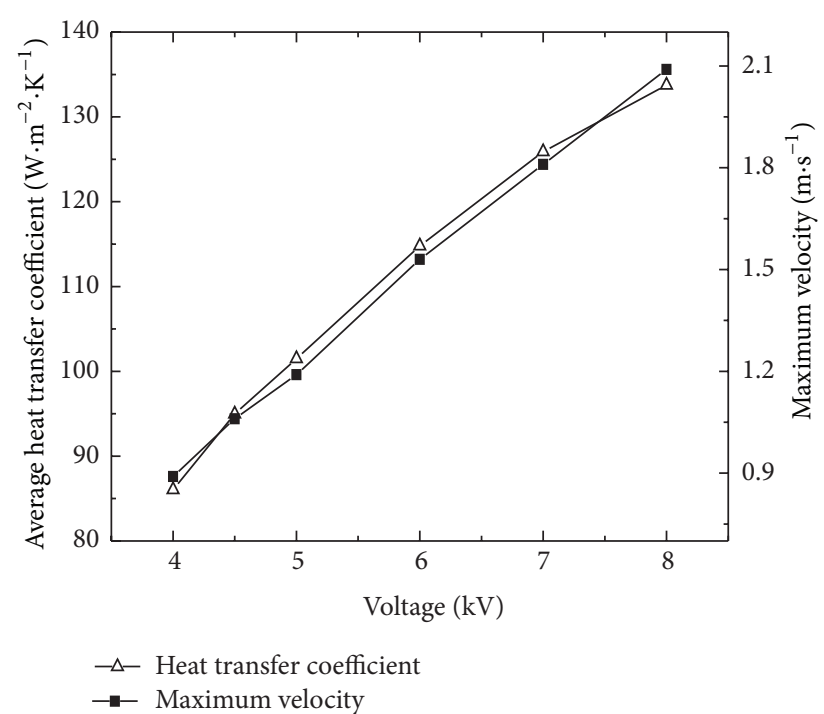

FIGURE 9: Effect of voltage on velocity and heat transfer.

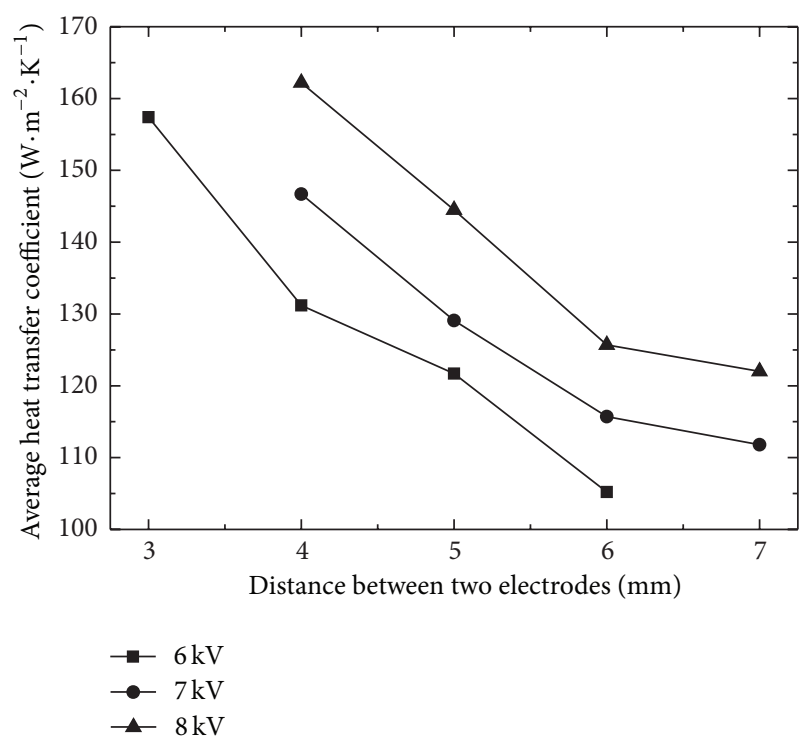

FIGURE 10: Effect of distance between two electrodes on heat transfer.

convection heat transfer increases with the decrease of the distance at the same applied voltage. The main reason is that the smaller distance between the two electrodes could lead to the increase of current (see Figure 11) and the speed of ionic wind (see Figure 12). The higher speed of the ionic wind results in the improvement of convection heat transfer coefficient. In addition, the heat transfer coefficients at the distance of $3 \mathrm{~mm}$ with the voltage of $6 \mathrm{kV}$ are quite close to the heat transfer coefficients at the distance of $4 \mathrm{~mm}$ with the voltage of $8 \mathrm{kV}$. This implies that different combinations of distances between electrodes and applied voltages can produce similar ionic wind cooling effect.

5.4. Effects of Plate Area on Heat Transfer. With fixed applied voltage $(7 \mathrm{kV})$, fixed distance between two electrodes $(4 \mathrm{~mm})$,

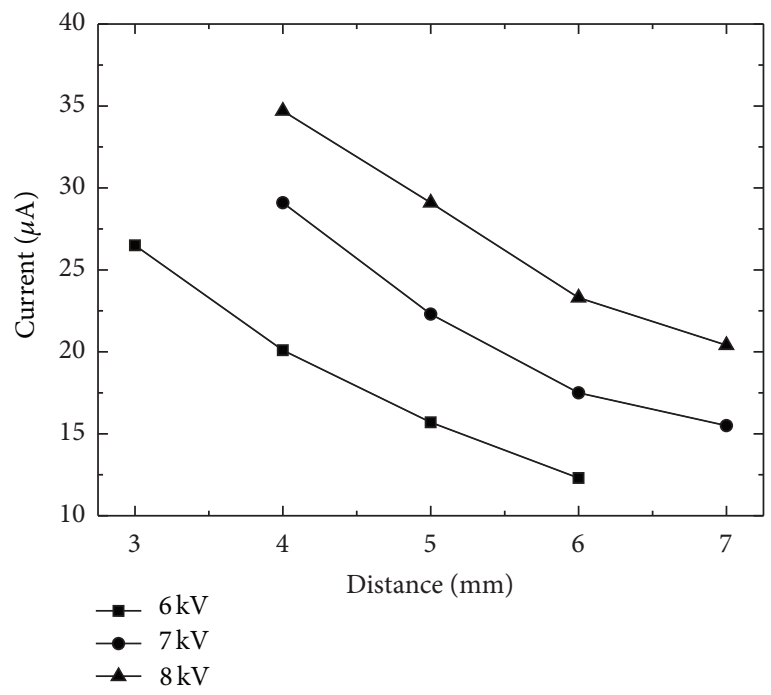

FIGURE 11: Effect of distance between two electrodes on current.

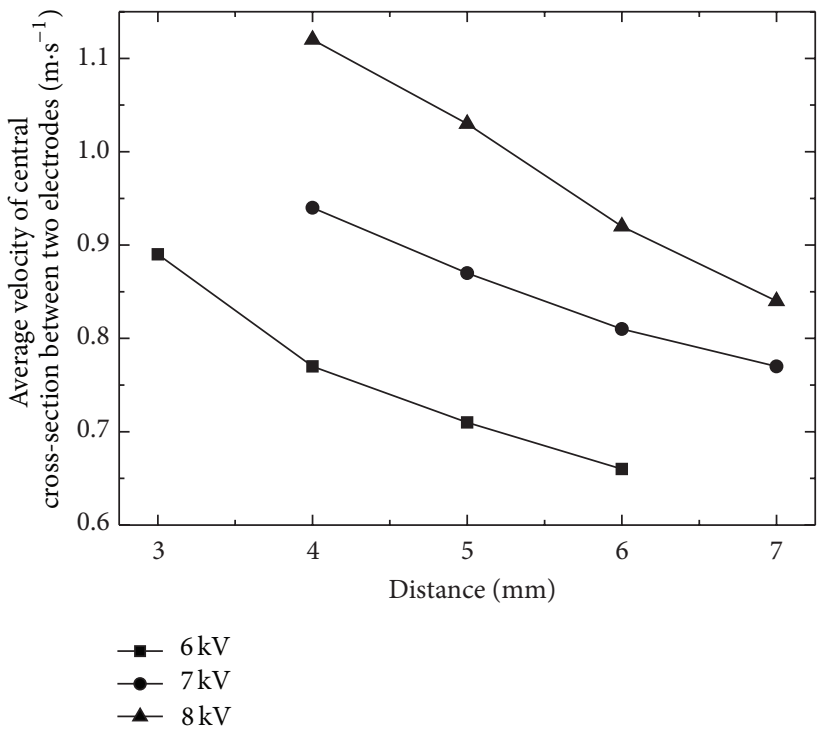

Figure 12: Effect of distance between two electrodes on velocity.

and fixed radius of the needle electrode $\left(8 \times 10^{-3} \mathrm{~mm}\right)$, the influence of the plate area on the heat transfer is shown in Figure 13.

It can be found that the heat transfer coefficient decreases with the increase of the plate area $(4 \mathrm{~mm} \times 4 \mathrm{~mm}, 5 \mathrm{~mm} \times$ $5 \mathrm{~mm}, 6 \mathrm{~mm} \times 6 \mathrm{~mm}$, and $8 \mathrm{~mm} \times 8 \mathrm{~mm})$. One reason is that the increase of plate area leads to the decrease of the density of electric field, which decreases the velocity of ionic wind as shown in Figure 13. Another reason is that the flow boundary layer thickness and thermal boundary thickness increase along with the increase of the length of plate, which results in the decrease of the heat transfer performance along the length of the plate and therefore causes the smaller average heat transfer coefficient. This trend can be seen from Figure 14.

5.5. Effects of Ratio between the Length of the Plate and the Distance of Two Electrodes on Heat Transfer. In this section, 


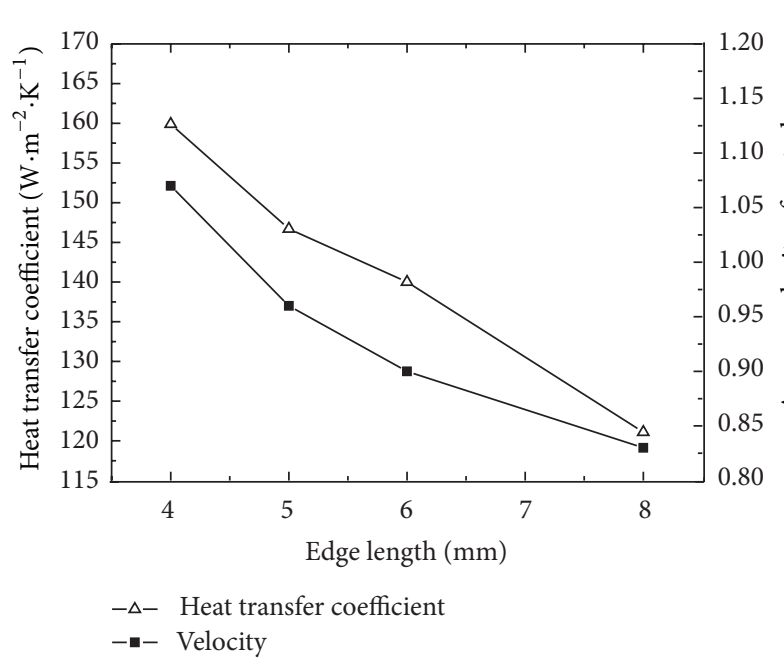

FIGURE 13: Effect of plate area on velocity and heat transfer.

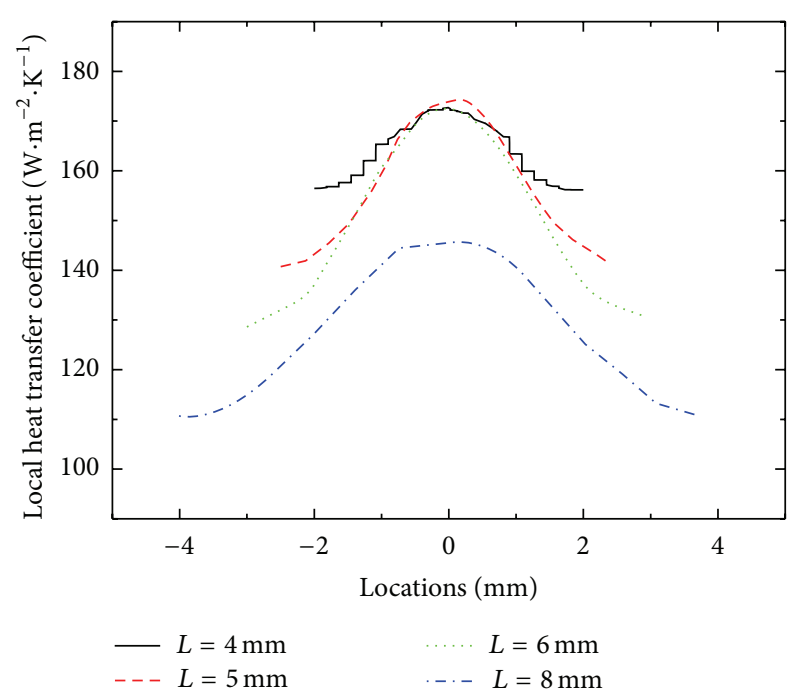

FIGURE 14: Variation of local heat transfer coefficient along the central line ( $y$ direction) of the plate surface.

the applied voltage is kept as $7 \mathrm{kV}$, and the ratios between the length of the square plate and the distance of two electrodes are $0.5,1.0$, and 1.5, respectively. As shown in Figure 15, smaller ratio leads to better heat transfer performance. The maximum heat transfer enhancement ratio $\Gamma$ could reach up to 22. At the fixed distance between two electrodes, the smaller ratio between the length of the plate and the distance of two electrodes means the smaller plate area, which can lead to better heat transfer performance as discussed in Section 5.4.

5.6. Effects of Different Combinations of Distances between Two Electrodes and Applied Voltages on Heat Transfer. In Figure 16, examples for different combinations of distance between two electrodes and applied voltage with similar heat transfer enhancement ratios are presented. As shown in Figure 16, the combination which has smaller distance

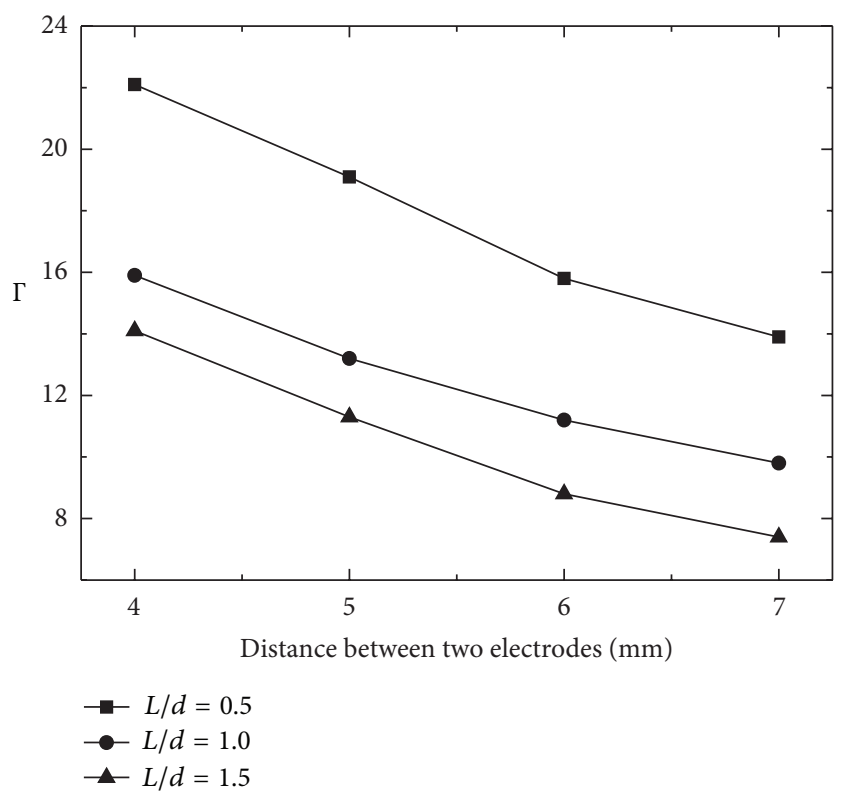

FIGURE 15: Effect of the ratio between the length of the plate and the distance of two electrodes on heat transfer.

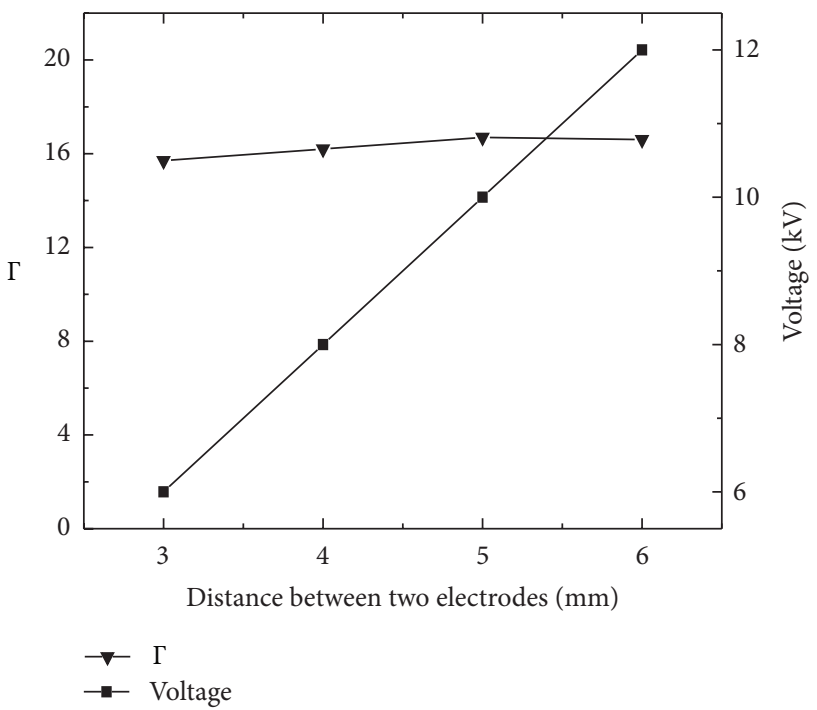

FIGURE 16: Effect of different combinations of the distance between two electrodes and the voltage on heat transfer.

between two electrodes needs lower applied voltage to achieve the same heat transfer enhancement ratio $(\Gamma \approx 16)$ as the combination which has the lager distance between two electrodes. It also can be observed in Figure 17 that under the same heat transfer enhancement ratio the electric power $P(P=I V)$ consumed by the device with smaller distance between two electrodes and lower applied voltage are less than the devices with larger distance and higher applied voltage. It obviously demonstrates that the smaller ionic wind device has more advantages on the operation voltage and energy saving than the larger one, and the smaller ionic wind device is more suitable for the requirement of the local cooling of miniaturized and portable equipment. 


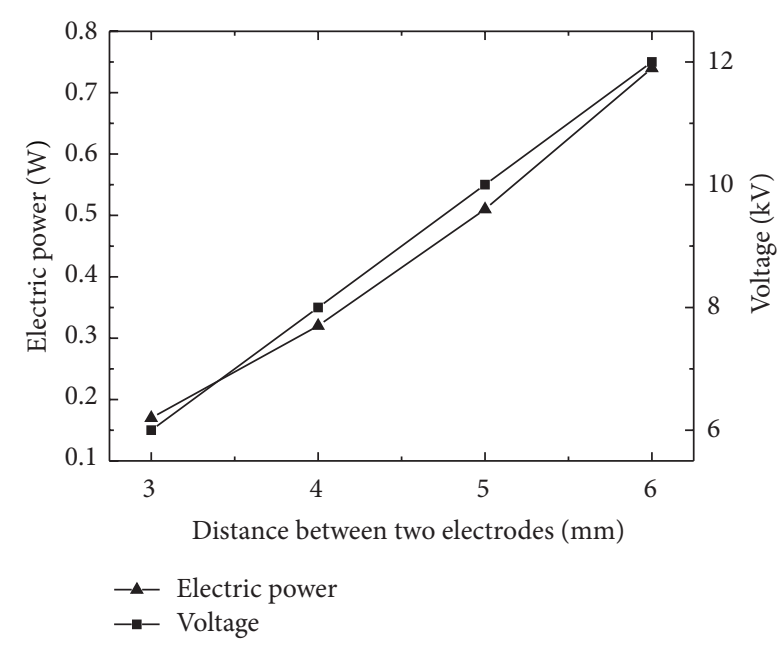

FIGURE 17: Electric power consumption and operation voltage of devices with different distances between two electrodes and fixed heat transfer enhancement ratio $(\Gamma \approx 16)$.

\section{Conclusions}

According to present study, the following main conclusions can be reached.

(1) The voltage is one of the main factors for the convection heat transfer under electric field, and the effectiveness of heat transfer is increased with the improvement of the voltage.

(2) The effectiveness of heat transfer increases with the diminution of the distance between the two electrodes and the area of the grounding plate. The smaller size is better for local ionic wind cooling under the same conditions.

(3) The smaller size ionic wind cooling device needs lower operation voltage and electric energy consumption to get higher heat transfer capacity. This provides an important theoretical support for the potential of the miniaturization of ionic wind devices and the application of ionic wind devices in the miniaturized and portable equipment.

\section{Notation}

\section{Latin Symbols}

A: Area, $\mathrm{mm}^{2}$

$D$ : Space charge diffusion coefficient

$E$ : Electric field intensity, $\mathrm{V} \cdot \mathrm{m}^{-1}$

$E_{b}$ : Breakdown electric field intensity, $\mathrm{V} \cdot \mathrm{m}^{-1}$

$F$ : Electric force, $\mathrm{N}$

I: Current, A

$J: \quad$ Current density, $\mathrm{A} \cdot \mathrm{m}^{-1}$

L: $\quad$ Length, $\mathrm{mm}$

$P$ : Electric power, $\mathrm{W}$

$Q_{E}$ : Joule heat, $\mathrm{W}$
$R:$ Radius, mm

T: Temperature, $\mathrm{K}$

$U$ : Velocity, $\mathrm{m} / \mathrm{s}$

$V$ : Voltage, $\mathrm{V}$

$c_{p}$ : Constant-pressure specific heat, $\mathrm{J} \cdot \mathrm{kg}^{-1} \cdot \mathrm{K}^{-1}$

$d$ : Distance between two electrodes, $\mathrm{mm}$

$h$ : Heat transfer coefficient, $\mathrm{W} \cdot \mathrm{m}^{-2} \cdot \mathrm{K}^{-1}$

$p$ : Pressure, $\mathrm{Pa}$

$q$ : Space charge density, $\mathrm{C} \cdot \mathrm{m}^{-3}$

$q_{t}$ : Heat flux, $\mathrm{W} / \mathrm{m}^{2}$.

\section{Greek Symbols}

$\Gamma:$ Heat transfer enhancement ratio

$\varepsilon: \quad$ Dielectric constant, $\mathrm{F} \cdot \mathrm{m}^{-1}$

$\lambda$ : Heat conductivity coefficient, $\mathrm{W} \cdot \mathrm{m}^{-1} \cdot \mathrm{K}^{-1}$

$\mu_{E}$ : Ionic mobility, $\mathrm{m}^{2} \cdot \mathrm{V}^{-1} \cdot \mathrm{s}^{-1}$

$\nu$ : Kinematic viscosity, $\mathrm{m}^{2} \cdot \mathrm{s}^{-1}$

$\rho:$ Density, $\mathrm{kg} \cdot \mathrm{m}^{-3}$.

\section{Subscripts}

0: Value of initial

$E$ : Value under electric field

EHD: Value of EHD

avg: Value of average

air: Value of air

cal: Value of calculation

$e$ : $\quad$ Electricity filed, electrode

exp: Value of experiment

free: Value of natural convection

$g$ : Value of ground electrode

$n$ : $\quad$ Value of needle electrode

num: Value of numerical

$x$ : Local value.

\section{Conflict of Interests}

The authors declare that there is no conflict of interests regarding the publication of this paper.

\section{Acknowledgments}

This work is supported by the National Natural Science Foundation of China (no. 51206129), Fok Ying Tung Education Foundation, and the Fundamental Research Funds for the Central Universities.

\section{References}

[1] E. Moreau and G. Touchard, "Enhancing the mechanical efficiency of electric wind in corona discharges," Journal of Electrostatics, vol. 66, no. 1-2, pp. 39-44, 2008.

[2] N. Kasayapanand, "Enhanced heat transfer in inclined solar chimneys by electrohydrodynamic technique," Renewable Energy, vol. 33, no. 3, pp. 444-453, 2008. 
[3] N. Kasayapanand, "Electrohydrodynamic enhancement of heat transfer in vertical fin array using computational fluid dynamics technique," International Communications in Heat and Mass Transfer, vol. 35, no. 6, pp. 762-770, 2008.

[4] N. Kasayapanand, "A computational fluid dynamics modeling of natural convection in finned enclosure under electric field," Applied Thermal Engineering, vol. 29, no. 1, pp. 131-141, 2009.

[5] N. Kasayapanand and T. Kiatsiriroat, "Enhanced heat transfer in partially open square cavities with thin fin by using electric field," Energy Conversion and Management, vol. 50, no. 2, pp. 287-296, 2009.

[6] S. R. Mahmoudi, K. Adamiak, P. Castle, and M. Ashjaee, "The effect of corona discharge on free convection heat transfer from a horizontal cylinder," Experimental Thermal and Fluid Science, vol. 34, no. 5, pp. 528-537, 2010.

[7] D. B. Go, S. V. Garimella, T. S. Fisher, and R. K. Mongia, "Ionic winds for locally enhanced cooling," Journal of Applied Physics, vol. 102, no. 5, Article ID 053302, 2007.

[8] D. B. Go, R. A. Maturana, T. S. Fisher, and S. V. Garimella, "Enhancement of external forced convection by ionic wind," International Journal of Heat and Mass Transfer, vol. 51, no. 2526, pp. 6047-6053, 2008.

[9] S. A. O. Ahmedou and M. Havet, "Effect of process parameters on the EHD airflow," Journal of Electrostatics, vol. 67, no. 2-3, pp. 222-227, 2009.

[10] M. S. Pour and E. Esmaeilzadeh, "Experimental investigation of convective heat transfer enhancement from 3D-shape heat sources by EHD actuator in duct flow," Experimental Thermal and Fluid Science, vol. 35, no. 7, pp. 1383-1391, 2011.

[11] A. Alamgholilou and E. Esmaeilzadeh, "Experimental investigation on hydrodynamics and heat transfer of fluid flow into channel for cooling of rectangular ribs by passive and EHD active enhancement methods," Experimental Thermal and Fluid Science, vol. 38, pp. 61-73, 2012.

[12] D. Schlitz and V. Singhal, "An electro-aerodynamic solid-state fan and cooling system," in Proceedings of the 24th Annual IEEE Semiconductor Thermal Measurement and Management Symposium (SEMI-THERM '08), pp. 46-49, San Jose, Calif, USA, March 2008.

[13] N. E. Jewell-Larsen, H. Ran, Y. Zhang, M. K. Schwiebert, K. A. Honer, and A. V. Mamishev, "Electrohydrodynamic (EHD) cooled laptop," in Proceedings of the 25th Annual IEEE Semiconductor Thermal Measurement and Management Symposium, pp. 261-266, San Jose, Calif, USA, March 2009.

[14] N. E. Jewell-Larsen, S. V. Karpov, H. Ran, P. Savalia, and K. A. Honer, "Investigation of dust in electrohydrodynamic (EHD) systems," in Proceedings of the 26th Annual IEEE Semiconductor Thermal Measurement and Management Symposium (SEMITHERM '10), pp. 249-255, February 2010.

[15] R.-T. Huang, W.-J. Sheu, and C.-C. Wang, "Heat transfer enhancement by needle-arrayed electrodes - an EHD integrated cooling system," Energy Conversion and Management, vol. 50, no. 7, pp. 1789-1796, 2009.

[16] R. Tirumala and D. B. Go, " The assisted corona discharge: multi-electrode configurations and the effects on EHD flows," in Proceedings of the ESA Annual Meeting on Electrostatics, 2010, paper F4.

[17] R. Tirumala and D. B. Go, "Multi-electrode assisted corona discharge for electrohydrodynamic flow generation in narrow channels," IEEE Transactions on Dielectrics and Electrical Insulation, vol. 18, no. 6, pp. 1854-1863, 2011.
[18] J. Zhang and F. C. Lai, "Effect of emitting electrode number on the performance of EHD gas pump in a rectangular channel," Journal of Electrostatics, vol. 69, no. 6, pp. 486-493, 2011.

[19] A. K. M. M. H. Mazumder and F. C. Lai, "Two-Stage electrohydrodynamic gas pump in a square channel," in Proceedings of the ESA Annual Meeting on Electrostatics, pp. 1-12, 2011.

[20] H.-C. Wang, N. E. Jewell-Larsen, and A. V. Mamishev, “Thermal management of microelectronics with electrostatic fluid accelerators," Applied Thermal Engineering, vol. 51, no. 1-2, pp. 190211, 2013.

[21] K. Adamiak and P. Atten, "Simulation of corona discharge in point-plane configuration," Journal of Electrostatics, vol. 61, no. 2, pp. 85-98, 2004.

[22] F. W. Peek, Dielectric Phenomena in High Voltage Engineering, McGraw-Hill, 1920.

[23] C.-P. Hsu, N. E. Jewell-Larsen, I. A. Krichtafovitch, and A. V. Mamishev, "Heat-transfer-enhancement measurement for microfabricated electrostatic fluid accelerators," Journal of Microelectromechanical Systems, vol. 18, no. 1, pp. 111-118, 2009.

[24] D. B. Go, S. V. Garimella, and T. S. Fisher, "Numerical simulation of microscale ionic wind for local cooling enhancement," in Proceedings of the 10th Intersociety Conference on Thermal and Thermomechanical Phenomena and Emerging Technologies in Electronic Systems (ITherm '06), pp. 45-53, San Diego, Calif, USA, June 2006. 


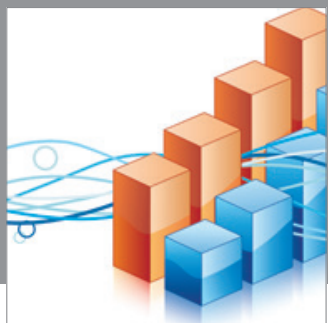

Advances in

Operations Research

mansans

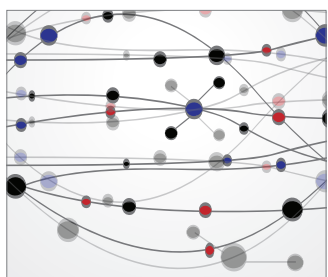

The Scientific World Journal
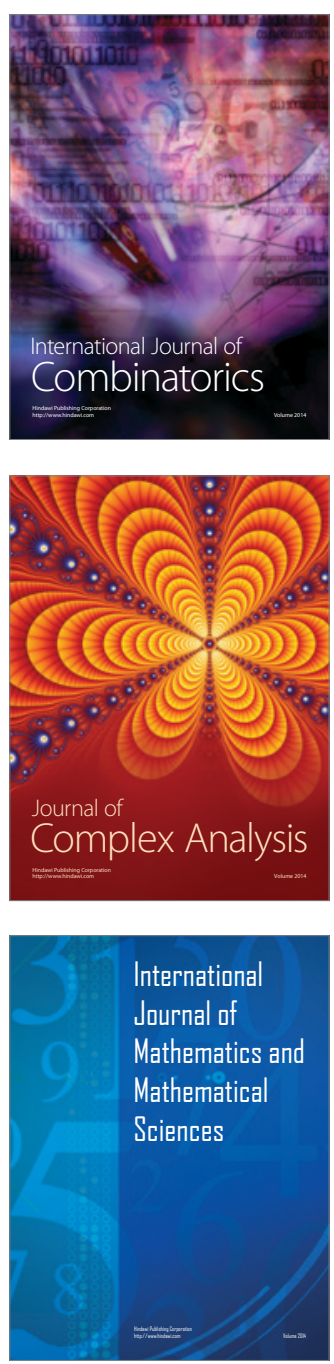
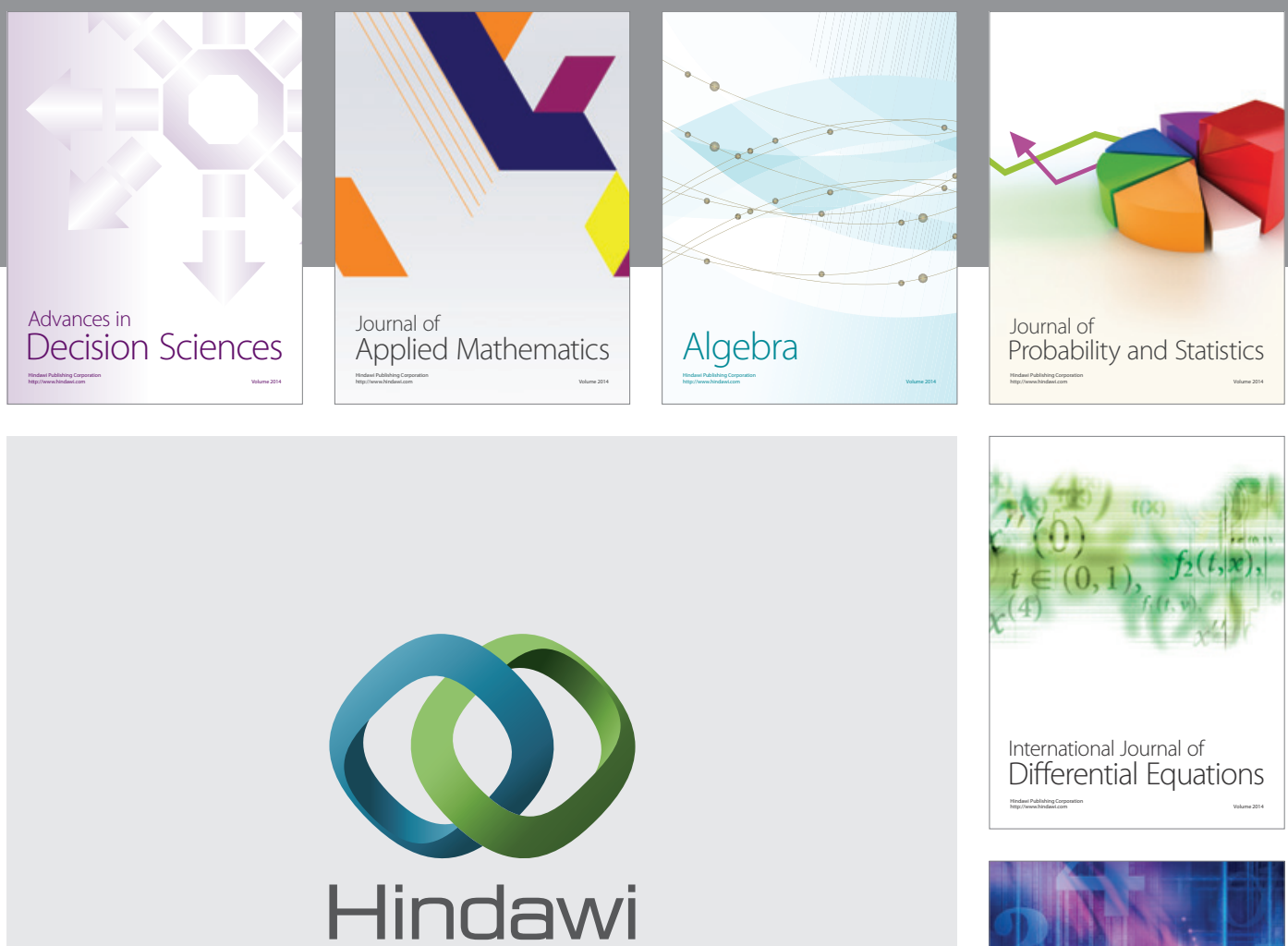

Submit your manuscripts at http://www.hindawi.com
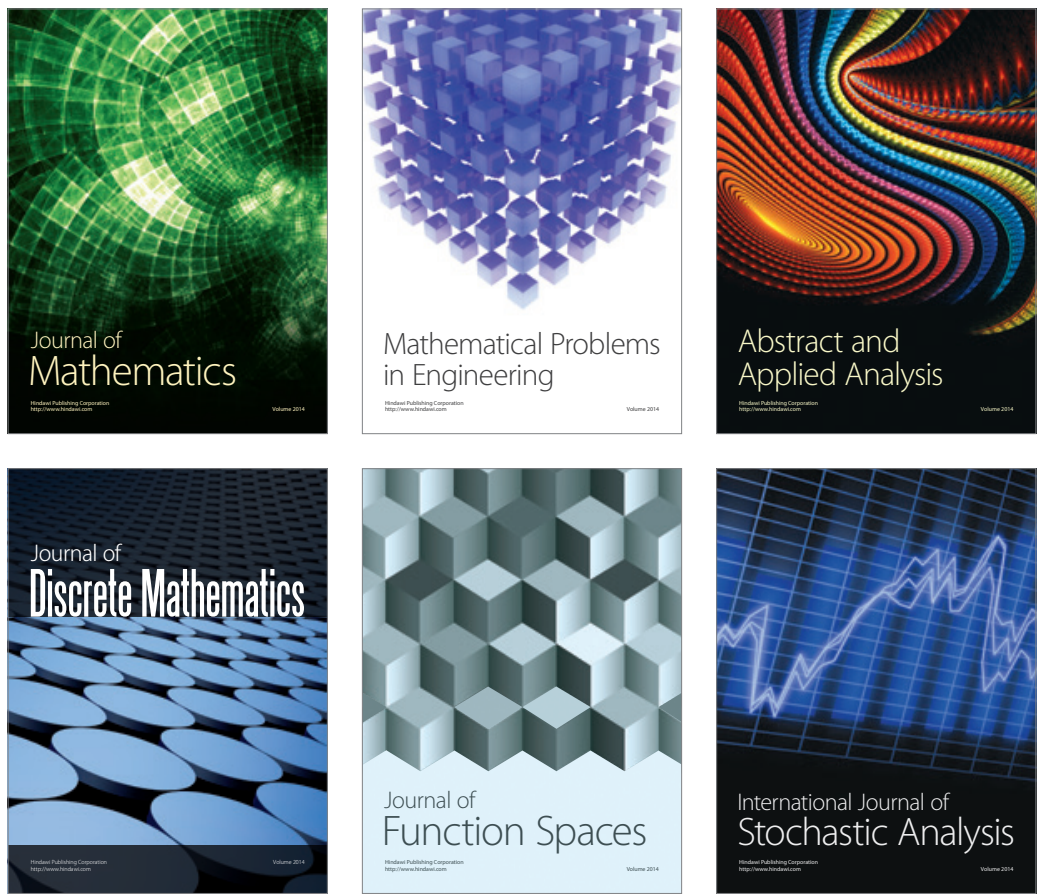

Journal of

Function Spaces

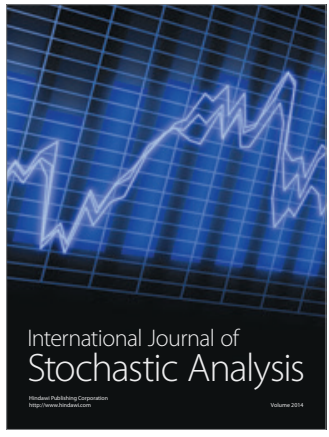

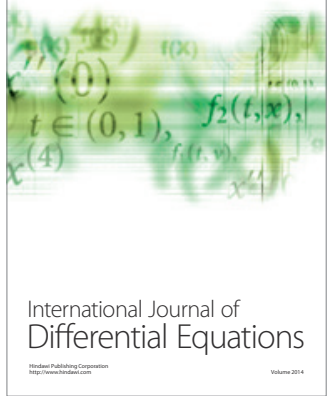
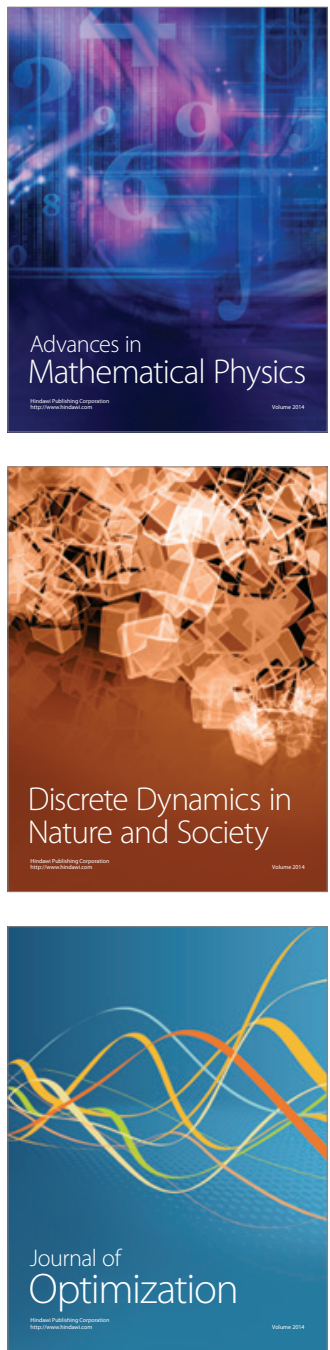